\section{Takotsubo Cardiomyopathy: A Recognizable Phenotype: Mid-Cavity Variant}

\author{
Nachiket J Patel ${ }^{1}$ and Timothy E Paterick ${ }^{2 *}$ \\ ${ }^{1}$ Department of Cardiology, University of Arizona Phoenix, Arizona, USA
}

${ }^{2}$ Department of Cardiology, Bay Care Clinic Green Bay, Wisconsin, USA

\begin{abstract}
Takotsubo cardiomyopathy is an important differential consideration when a patient presents with an acute coronary syndrome. $\mathrm{Pa}$ tients typically present with chest pain/pressure, shortness of breath, electrocardiographic changes, elevated biomarkers, normal or near normal coronary arteries, and wall motion abnormalities that are not consistent with a single coronary vascular bed. This constellation of findings is often associated with a precipitating emotional or physical stressor.

Variants of the classic left ventricular apical ballooning syndrome, including mid- and basal left ventricular wall motion abnormalities, are being more frequently recognized. The recognition and diagnosis of takotsubo cardiomyopathy has important implications for clinical management initially and in follow up. A small subset of patients may experience life-threatening complication during initial presentation, however, most patient recover and have a favorable longterm prognosis. The pathophysiology of takotsubo cardiomyopathy remains an enigma, but a surfeit of catecholamines seems pertinent to the underlying pathophysiology.
\end{abstract}

Keywords: Acute and long-term treatment; Acute coronary syndrome; Angiography; Electrocardiography; Mid-ventricular variant of takotsubo cardiomyopathy; Takotsubo cardiomyopathy phenotypes

${ }^{*}$ Corresponding author: Timothy E Paterick, Department of Cardiology, Bay Care Clinic Green Bay, Wisconsin, USA, Tel: +1 9044764233; E-mail: tpaterick@gmail.com

Citation: Patel NJ, Paterick TE (2018) Takotsubo Cardiomyopathy: A Recognizable Phenotype: Mid-Cavity Variant. J Cardiol Stud Res 4: 013.

Received: October 01, 2018; Accepted: October 29, 2018; Published: November 12, 2018

Copyright: (c) 2018 Patel NJ and Paterick TE. This is an open-access article distributed under the terms of the Creative Commons Attribution License, which permits unrestricted use, distribution, and reproduction in any medium, provided the original author and source are credited.

\section{Introduction}

Takotsubo Cardiomyopathy (TC) is a unique cardiomyopathy that is an important etiologic consideration in the differential diagnosis of acute coronary syndrome. The presenting symptoms and signs are similar to acute coronary syndrome after plaque rupture, but important distinctions include absence of coronary occlusion and wall motion abnormalities that do fit with a single vascular territory. TC usually has an emotional or physical stressor. The acute presentation of TC can include life-threatening hemodynamic compromise, but the longterm prognosis is better than the prognosis associated with acute coronary syndrome [1]. There are several morphological variants of TC that include apical segment, mid-ventricular, and basal involvement. Apical and mid segment involvement may occur together. Echocardiography is fundamental to identifying the various phenotypes of TC. The mid-ventricular variant of TC is characterized by transient hypokinesis, akinesis or dyskinesis of the left ventricular mid segments with normal to hyperkinesia of apical and basal segments. There is no acute plaque rupture. There are new electrocardiographic changes including: ST elevation and/or $t$ wave inversion and modest elevation of cardiac biomarkers [2].

\section{Case Report}

59 year-old female presents with chest tightness and dyspnea. Symptoms occurred after a stressful conversation about the custody of her disabled 37-year-old son. On arrival to the emergency room she had an immediate ECG revealing $t$ wave inversion V1-6 (Figure 1). This was compared to a normal ECG one year earlier (Figure 2).

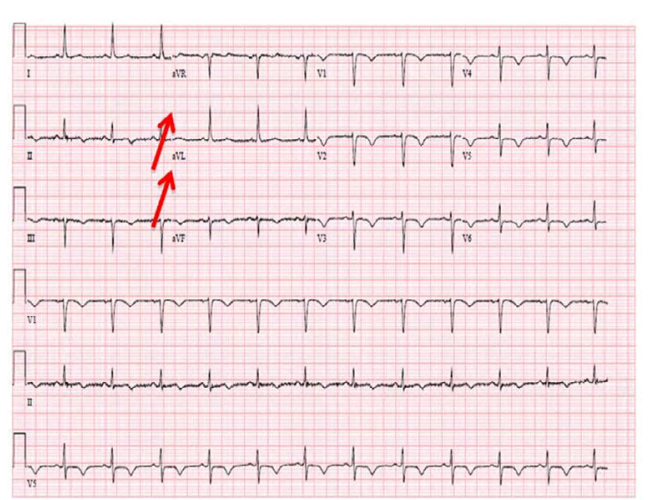

Figure 1: ECG revealing $t$ wave inversion across the pericardium (Red arrows pointing to inverted $t$ waves).

The initial troponin was elevated at $0.13 \mathrm{ng} / \mathrm{ml}(<0.05 \mathrm{ng} / \mathrm{ml})$. The patient was taken to the cardiac catheterization and found to have mild coronary artery disease manifest has a proximal $40 \%$ left anterior descending narrowing (Figure 3).

Contrast LV ventriculography did not reveal any segmental abnormalities (Figure 4). Post cardiac catheterization echocardiography revealed reduced Left Ventricular (LV) systolic function with mid LV 
cavity segment hypokinesis with normal thickening of the apical and basal segments (Figure 5). The troponin level peaked at $0.38 \mathrm{ng} / \mathrm{ml}(<$ $0.05 \mathrm{ng} / \mathrm{ml})$. The patient recovered in the hospital without hemodynamic or electrical disturbance.

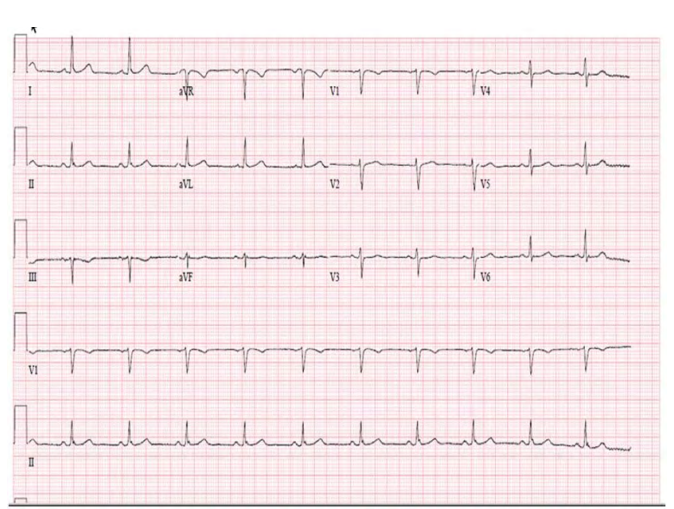

Figure 2: Normal ECG one year before when the patient was free of symptoms.

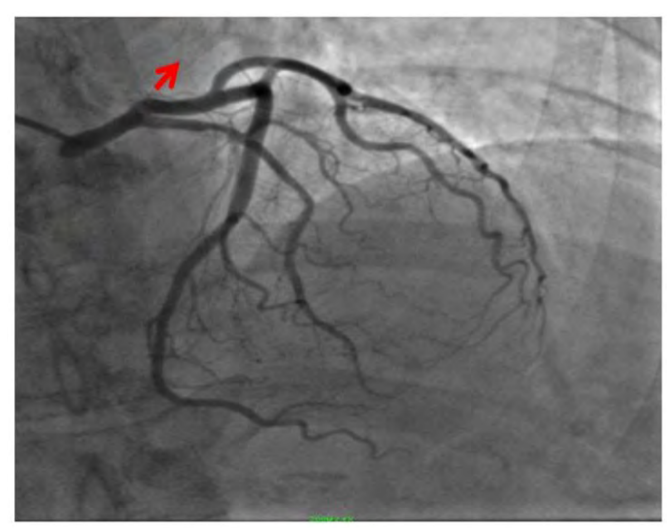

Figure 3: $40 \% \mathrm{LAD}$ narrowing (red arrow pointing to the LAD lesion).

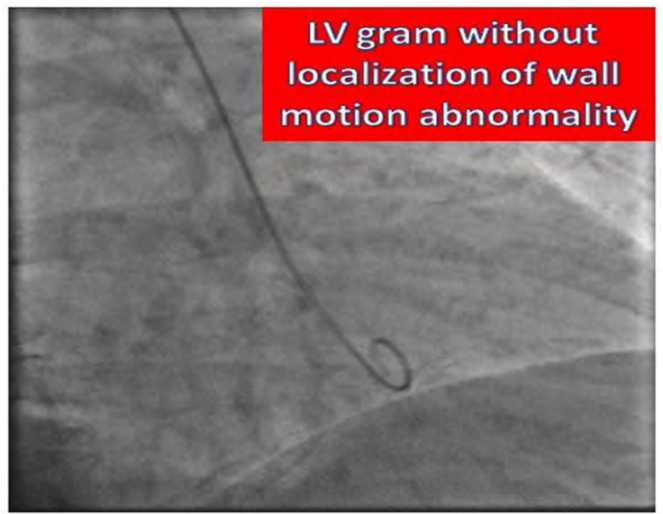

Figure 4: LV Gram: RAO.

The patient returned 6 weeks later and she was free of symptoms with robust activities. Echocardiography revealed normal LV systolic function with normal wall motion of all segments (Figure 6).
A nuclear stress test revealed normal perfusion. The patient had all the classic features of mid-cavity variant of TS cardiomyopathy.

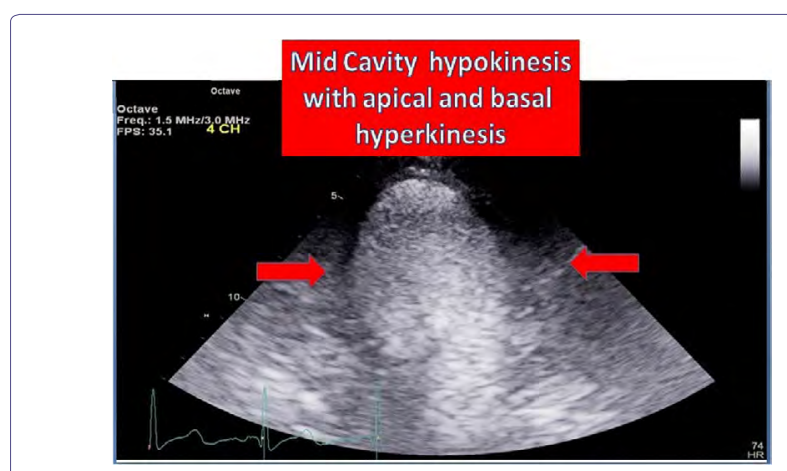

Figure 5: Modified apical 4 chambers: Mid-ventricular segment hypokinesis.

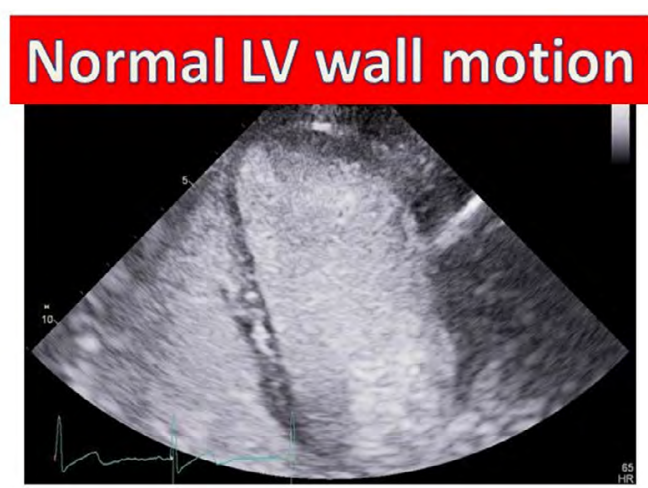

Figure 6: Modified apical 4 chamber: Recovery of LV function 6 weeks post acute presentation.

\section{Classic Features of Takotsubo Cardiomyopathy}

\section{Presentation}

Chest pain is the most common presenting symptom (80\%). Dyspnea and pulmonary edema occur roughly $20 \%$ of the time. Cardiac arrest, cardiogenic shock, hemodynamically significant arrhythmias are infrequent [1]. An emotional or physical stressor is common. Common triggers include death of a loves one and anxiety and pain related to medical procedures and operations. Less common triggers include opiate withdrawal, cocaine use, dobutamine stress testing, intravenous ergonovive, and thyroid storm. TC should be considered in the differential thought process for postmenopausal women who present with symptoms of myocardial ischemia who experience emotional or physical stress.

\section{Prevalence}

More than $80 \%$ of TC cases occur in postmenopausal age $65-72$ years. There is available data suggesting that $1 / 30$ patients having cardiac catheterization have a variant of TC. The best estimates suggest that $0.7 \%$ to $2.2 \%$ of patients presenting with suspected acute coronary syndrome have symptoms and ECG findings consistent with stress induced cardiomyopathy [3]. Increased awareness and recognition may elevate the estimated prevalence. 
Typically apical or mid-ventricular segment akinesia of the left ventricle (or both) is present. Also, not common is isolated mid-ventricular segment akinesia with apical sparing (Our case). It has been reported that as many as $40 \%$ of the TC cases are the mid-ventricular variant [4]. Basal akinesia with mid cavity and apical sparing has been identified [5]. There is no evidence identifying different pathophysiologic mechanisms for the phenotypic variant of TC.

\section{Electrocardiography and coronary angiography}

ECG findings in TC are variable with $1 / 3$ of patients having ST elevation with the anterior leads being the most common involvement. Another frequent presentation is ECGs with deep $t$ wave inversions and non-specific ST-T changes. Prolongation of the QT interval occurs, but torsade de pointe is rare. The ECG changes may be dependent upon the morphological variant of the presenting TC. Typically there is absence of obstructive coronary artery disease or acute plaque rupture identified at catheterization. Stable non-obstructive coronary artery disease may accompany TC syndrome. Left ventriculography may be helpful in identifying apical and basal variant of TC but seem less helpful with the mid-cavity variant.

\section{Cardiac biomarkers}

The biomarker troponin is typically elevated upon presentation with TC and is evidence of myonecrosis. Troponin typically peaks after 24 hours, but blood levels are lower than would be expected on the basis of ECG changes and the extent of wall motion abnormality. There are cases where myonecrosis is insignificant and cardiac magnetic resonance imaging reveals an absence of gadolinium hyperenhancement [6].

\section{Treatment: Acute, Sub-acute and Long-term}

\section{Acute treatment}

Patients with TC should be treated analogous to patient with acute coronary syndrome. The initial analysis should be coronary angiography and cardiac imaging. Imaging is critical in situations when fibrinolysis therapy is being considered with a ST elevation presentation. The differential diagnosis of hemodynamically significant hypotension in a TC patient is pump failure or dynamic outflow tract obstruction. It is important to recognize this differential and imaging will identify the etiology of the hemodynamic instability. Pump failure may require intravenous pressor support and mechanical support with an intra-aortic balloon. Alternatively, with outflow tract obstruction inotropic agents are contraindicated and treatment should include intravenous fluids, short acting beta-blockers, and peripheral vasoconstrictors such as phenylephrine are indicated [7]. Mechanical complications in TC, such as rupture, are rare [8]. Right ventricular involvement is TC occurs and involvement at presentation may predict adverse outcomes. Electrical complications such as atrial fibrillation, ventricular tachycardia, and ventricular fibrillations occur with $\mathrm{TC}$ and appear to be related to elevated catecholamine levels.

\section{Sub-acute and long-term treatment}

Only a small number of cases of TC-related death have been reported. Death prior to hospitalization is described but the incidence is unknown [9]. Complete recovery of left ventricular systolic function is essential to confirm the diagnosis. Recovery time is variable ranging from days to several weeks [1]. Medical treatment is empiric with beta-blockers and angiotensin-converting enzyme inhibitors until left ventricular function recovers. Left ventricular thrombus has been reported [3]. Anticoagulation therapy must be individualized based upon the degree and duration of akinesis. Recurrence occurs in $10 \%$ of patients [10]. The long-term use of beta-blockers has not been studied to determine efficacy.

\section{Conclusion}

Mid-ventricular variant of takotsubo cardiomyopathy is a recognizable phenotype that requires a high index of clinical suspicion and meticulous echocardiographic imaging. Echocardiography is the imaging modality of choice to clearly delineate the mid cavity hypokinesis.

\section{References}

1. Sharkey SW, Lesser JR, Zenovich AG, Maron MS, Lindberg J, et al. (2005) Acute and reversible cardiomyopathy provoked by stress in women from the United States. Circulation 111: 472-479.

2. Prasad A, Lerman A, Rihal CS (2008) Apical ballooning syndrome (Tako-Tsubo or stress cardiomyopathy): A mimic of acute myocardial infarction. Am Heart J 155: 408-417.

3. Roseberry BJ, Paterick TE (2009) Takotsubo cardiomyopathy resulting in left ventricle thrombus. Cardiology Review 26: 45-47.

4. Kurowski V, Kaiser A, von Hof K, Killerman DP, Mayer B, et al. (2007) Apical and midventricular transient left ventricular dysfunction syndrome (tako-tsubo cardiomyopathy): Frequency, mechanisms, and prognosis. Chest 132: 809-816.

5. Reuss CS, Lester SJ, Hurst RT, Askew JW, Nagor P, et al. (2007) Isolated left ventricular basal ballooning phenotype of transient cardiomyopathy in young women. Am J Cardiol 99: 1451-1453.

6. Wittenstein IS, Thiemann DR, Lima JAC, Baughman KL, Schulman SP, et al. (2005) Neurohumoral features of myocardial stunning due to sudden emotional stress. The New England Journal of Medicine 352: 539-548.

7. Yoshioka T, Hashimoto A, Tsuchihashi K, Nagao K, Kyuma M, et al. (2008) Clinical implications of midventricular obstruction and intravenous propranolol use in transient left ventricular apical ballooning (Tako-tsubo cardiomyopathy). Am Heart J 155: 526.

8. Akashi YJ, Tejima T, Sakurada H, Matsuda H, Suzuki K, et al. (2004) Left ventricular rupture associated with Takotsubo cardiomyopathy. Mayo Clin Proc 79: 821-824.

9. Raddino R, Pedrinazzi C, Zanini G, Robba D, Portera C, et al. (2008) Out-of-hospital cardiac arrest caused by transient left ventricular apical ballooning syndrome. Int J Cardiol 128: 31-33.

10. Bybee KA, Prasad A, Barsness GW, Lerman A, Jaffe AS, et al. (2004) Clinical characteristics and thrombolysis in myocardial infarction frame counts in women with transient left ventricular apical ballooning syndrome. Am J Cardiol 94: 343-346. 


\section{Hit \\ Hetario}

Journal of Anesthesia \& Clinical Care

Journal of Addiction \& Addictive Disorders

Advances in Microbiology Research

Advances in Industrial Biotechnology

Journal of Agronomy \& Agricultural Science

Journal of AIDS Clinical Research \& STDs

Journal of Alcoholism, Drug Abuse \& Substance Dependence

Journal of Allergy Disorders \& Therapy

Journal of Alternative, Complementary \& Integrative Medicine

Journal of Alzheimer's \& Neurodegenerative Diseases

Journal of Angiology \& Vascular Surgery

Journal of Animal Research \& Veterinary Science

Archives of Zoological Studies

Archives of Urology

Journal of Atmospheric \& Earth-Sciences

Journal of Aquaculture \& Fisheries

Journal of Biotech Research \& Biochemistry

Journal of Brain \& Neuroscience Research

Journal of Cancer Biology \& Treatment

Journal of Cardiology \& Neurocardiovascular Diseases

Journal of Cell Biology \& Cell Metabolism

Journal of Clinical Dermatology \& Therapy

Journal of Clinical Immunology \& Immunotherapy

Journal of Clinical Studies \& Medical Case Reports

Journal of Community Medicine \& Public Health Care

Current Trends: Medical \& Biological Engineering

Journal of Cytology \& Tissue Biology

Journal of Dentistry: Oral Health \& Cosmesis

Journal of Diabetes \& Metabolic Disorders

Journal of Dairy Research \& Technology

Journal of Emergency Medicine Trauma \& Surgical Care

Journal of Environmental Science: Current Research

Journal of Food Science \& Nutrition

Journal of Forensic, Legal \& Investigative Sciences

Journal of Gastroenterology \& Hepatology Research
Journal of Gerontology \& Geriatric Medicine

Journal of Genetics \& Genomic Sciences

Journal of Hematology, Blood Transfusion \& Disorders

Journal of Human Endocrinology

Journal of Hospice \& Palliative Medical Care

Journal of Internal Medicine \& Primary Healthcare

Journal of Infectious \& Non Infectious Diseases

Journal of Light \& Laser: Current Trends

Journal of Modern Chemical Sciences

Journal of Medicine: Study \& Research

Journal of Nanotechnology: Nanomedicine \& Nanobiotechnology

Journal of Neonatology \& Clinical Pediatrics

Journal of Nephrology \& Renal Therapy

Journal of Non Invasive Vascular Investigation

Journal of Nuclear Medicine, Radiology \& Radiation Therapy

Journal of Obesity \& Weight Loss

Journal of Orthopedic Research \& Physiotherapy

Journal of Otolaryngology, Head \& Neck Surgery

Journal of Protein Research \& Bioinformatics

Journal of Pathology Clinical \& Medical Research

Journal of Pharmacology, Pharmaceutics \& Pharmacovigilance

Journal of Physical Medicine, Rehabilitation \& Disabilities

Journal of Plant Science: Current Research

Journal of Psychiatry, Depression \& Anxiety

Journal of Pulmonary Medicine \& Respiratory Research

Journal of Practical \& Professional Nursing

Journal of Reproductive Medicine, Gynaecology \& Obstetrics

Journal of Stem Cells Research, Development \& Therapy

Journal of Surgery: Current Trends \& Innovations

Journal of Toxicology: Current Research

Journal of Translational Science and Research

Trends in Anatomy \& Physiology

Journal of Vaccines Research \& Vaccination

Journal of Virology \& Antivirals

Submit Your Manuscript: http://www.heraldopenaccess.us/Online-Submission.php 